\title{
Perceived Clinical Competence among Undergraduate Nursing Students in the University of Gondar and Bahir Dar University, Northwest Ethiopia: A Cross-Sectional Institution Based Study
}

\author{
Berhanu Boru Bifftu, ${ }^{1}$ Berihun Assefa Dachew, ${ }^{2}$ Bewket Tadesse Tiruneh, ${ }^{1}$ \\ Mengistu Mekonnen Kelkay, ${ }^{1}$ and Netsanet Habte Bayu ${ }^{1}$ \\ ${ }^{1}$ Department of Nursing, University of Gondar College of Medicine and Health Sciences, P.O. Box 196, Gondar, Ethiopia \\ ${ }^{2}$ Institute of Public Health, Department of Epidemiology and Biostatistics, University of Gondar College of \\ Medicine and Health Sciences, P.O. Box 196, Gondar, Ethiopia \\ Correspondence should be addressed to Berhanu Boru Bifftu; berhanuboru@gmail.com
}

Received 15 January 2016; Revised 31 March 2016; Accepted 26 April 2016

Academic Editor: Violeta Lopez

Copyright ( 2016 Berhanu Boru Bifftu et al. This is an open access article distributed under the Creative Commons Attribution License, which permits unrestricted use, distribution, and reproduction in any medium, provided the original work is properly cited.

\begin{abstract}
Introduction. To produce competent, confident, critical thinker with the ability to lead, to question, and to be questioned is needed in nursing education. This study aimed to assess perceived clinical competence among nursing students. Methods. This cross-sectional study was conducted in two nursing schools in Ethiopia. Data were collected using pretested, semistructured questionnaire. Clinical competence was measured by Short Nursing Competence Questionnaires. Binary logistic regression model was fitted to identify associated factors. An adjusted odds ratio with $95 \%$ confidence interval was computed. Results. Overall, $48.7 \%$ of the participants perceived themselves as clinically competent. Social support [moderate (AOR $=5.87$, CI: 1.346, 9.586), high $(\mathrm{AOR}=6.27$, CI: $1.741,7.608)$ ], type of institution [ $(\mathrm{AOR}=3.20, \mathrm{CI}: 1.331,7.694)]$, year of study [(AOR $=1.89(4.760,18.510)]$, attending theoretical classes [(AOR $=0.83 \mathrm{CI}: 0.017,0.412)$ ], and clinical environment [poor (AOR = 5.65, CI: 1.837, 13.453), fair $(\mathrm{AOR}=7.31, \mathrm{CI}: 2.790$, 15.356), good (AOR = 9.31, CI: 3.260, 19.967)] were associated with clinical competence. Conclusion. More than half of the study participants perceived themselves as incompetent. Social support, type of institution, year of study, attending theory classes, and clinical environment were associated with perceived clinical competence. Authors suggested that nursing students attend their theoretical class and utilize the available resource.
\end{abstract}

\section{Introduction}

The demographic changes of the population, increased technological advancements, and increased prevalence of chronic illnesses and disabilities have resulted in the need for changing the healthcare delivery systems [1]. This dynamic and uncertain nature of healthcare environment requires competent professional nurse to manage the rapidly changing environment [2]. But practically there is shortage of competent experienced nurses globally [3]; as a result, healthcare administrators face challenges to get competent and experienced nurses and are forced to find an option such as hiring newly graduated nurses to function independently and fill the shortage of competent and experienced nurses
[2]. Yet the challenge is lack of clinical competent graduates [4] because even if at the end of graduation period the nursing students are expected to achieve the maximum level of clinical competence, the existing evidences indicated a gap between theory and practice [4-7].

Competence refers to a person's essential skill related to job performance [8]. It is defined in the context of particular knowledge, attitude, and skill to perform a specific task in a manner that yields desirable outcomes [2]. However, its definition varies, based on healthcare providers' level of professional education and experience; nursing competence is defined as the persons' ability to perform nursing duties effectively to integrate cognitive, emotional, and psychomotor skills during nursing cares [9]. International Council of 
Nurses calls for the need of professional competence as a professional responsibility and public concern [10].

The need to produce a competent, confident, critical thinker with the ability to lead, to question, and to be questioned is the core of modern preregistration in nursing educational programmes. Despite these qualified professionals' need, nowadays clinical competence of nurses in hospitals and other clinical environments is the concern and the center of attention for managers and the healthcare systems [11]. Currently, lack of nurses' clinical competence is one of the most important issues in the provision of quality nursing care $[12,13]$. Thus, the need to reform nursing educational programs with much emphasis on clinical competence is needed to satisfy the need of concerned body [14].

Therefore, nursing faculties are one of the organizations responsible to train nurses who have high level of clinical competence to satisfy the needs of all concerned bodies. For the preparation of these incompetent graduated nurses, literature revealed the contributions of different factors. For example, clinical environment with good physical conditions had a positive influence on students' clinical learning. These included the pedagogical atmosphere of the environment, leadership style of the ward manager, premises of nursing on the ward, relationship role of the nurse teacher as enabling the integration of theory and practice, and the relationship among student, mentor, and nurse teacher [15]. Work experience, motivation, theoretical knowledge, and individual characteristic were also factors that affect the clinical competence of the students $[16,17]$.

However, studies revealed that the clinical competence of graduated nurses in hospitals and other functioning areas is the concern and the center of attention for the managers, professional associations, government, and society as a whole. In Ethiopia, lack of nurses' clinical competence is one of the most important reasons for the change of educational curriculum from a three-year program to a four-year program [18]. Therefore, in light of the tremendous increase in accelerated nursing programs targeted for enrollment, evaluating their clinical competence and indicating factors affecting the clinical competence of student nurses are important to design an effective educational program and prepare newly graduated competent nurses. Thus, the main purpose of this study was to assess the perceived clinical competence and associated factors among undergraduate nursing students in The University of Gondar and Bahir Dar University.

\section{Methods}

2.1. Study Design and Periods. Institution based crosssectional quantitative study design was employed from April 28 to $30,2015$.

2.2. Study Area. This study was conducted at The University of Gondar and Bahir Dar University. The University of Gondar is located 748 kilometers away from the capital city of Ethiopia, Addis Ababa. Bahir Dar University is also one of the universities in the country and located 560 kilometers away from the capital city of Ethiopia, Addis Ababa. In Ethiopia all of the higher governmental universities use the same curriculum which is nationally modularized.

2.3. Participants. The participants of this study were all third- and fourth-year undergraduate nursing students who completed their first semester clinical attachment at The University of Gondar and Bahir Dar University.

2.4. Instruments. Data collection instruments consisted of sociodemographic questionnaire (age, sex, marital status, religion, job, social support, year of study, and attending theoretical class, skill lab, and clinical ward). For the assessment of clinical competence, the Short Nursing Competencies Questionnaire (SNCQ) was used [14]. SNCQ is an 18-item scale developed from the 78-item Nursing Competencies Questionnaire [19]. The SNCQ was developed to measure the competence of nursing and midwifery students according to how often they engage in activities ranging from fundamental aspects of nursing care (e.g., giving emotional support) to more advanced competencies (e.g., planning and implementing health teaching). It has a four-point response format (always $=4$, usually $=3$, occasionally $=2$, and never $=1$ ) and scores range within 18-72 with a score of 72 being the highest level of self-reported competency. Cronbach's alpha for SNCQ in this study was 0.88. For the assessment of perceived social support, the 12 -item multidimensional scale of perceived social support was utilized. All items of perceived social support were measured on a 1-7-point Likert scale $(1=$ very strongly disagree to $7=$ very strongly agree $)$. The total sum of the 12 items ranges within 7-84. High level of perceived social support was defined as a score of 69-84 of the sum of social support scale, moderate level of perceived social support was defined as a score of 49-68 of the sum of social support scale, and low level of perceived social support was defined as a score of 12-48 of the total sum of social support scale [20]. Furthermore, we used one question to assess the overall clinical environment of the students using "overall, how can you evaluate your clinical practicum sites?" Possible responses to this question were (1) would not recommend, (2) poor, (3) fair, (4) good, and (5) very good.

2.5. Data Collection Method. Data were collected using a pretested semistructured questionnaire by self-administered method.

2.6. Data Processing and Analysis. Data cleanup and crosschecking were carried out before the analysis. EPI info version 3.5.3 statistical software for data entry and SPSS version 20 programs for analysis were utilized. Bivariate and multivariate logistic regressions were used to identify the associated factors. An adjusted odds ratio with 95\% confidence interval was used to identify the strength of the associated factors with perceived clinical competence. All factors with a $p$ value $<0.2$ in the bivariate logistic regression were entered into the multivariate model to control the possible effect of confounders. From multivariate logistic regression, variables with $p$ value $(p<0.05)$ were accepted. 
2.7. Ethical Consideration. A formal letter of permission was obtained from The Ethical Review Board of The University of Gondar. Then, this letter of permission was submitted to the respective nursing departments. Finally, after permission was obtained from the schools of nursing, information about the study was given to the study participants and for those who agreed to participate in the study written informed consent was sought.

\section{Results}

A total of 243 study participants enrolled in the study with a response rate of $90.7 \%$.

3.1. Sociodemographic Characteristics. The majority of the study participants were men, 176 (75.2\%). The mean ( \pm standard deviation) ages of the participants were 22.46 $( \pm 2.37)$ years. Two hundred and twenty-four $(95.7 \%)$ participants were single in marital status, 134 (57.3\%) were fourthyear students, and $168(71.8 \%)$ were Orthodox by religion. Out of 234 participants, 18 (7.7\%) had an additional job other than learning, 72 (30.8\%) had good social support, and 138 (59\%) were from Gondar University. Regarding the learning and teaching process, the majority of the participants 218 (93.2\%) attended all theoretical classes, 188 (80.3\%) attended all demonstration classes, and $216(92.3 \%)$ attended all clinical practice (Table 1).

3.2. Students' Perceptions of Their Clinical Environments. Regarding the perception of students toward their clinical environment, $58(24.8 \%)$ of the study participants rated the clinical environment as good, while 22 (9.4\%) were not recommended to others.

3.3. Perceived Clinical Competency. Overall, $48.7 \%$ of the study participants perceived themselves as having high clinical competence. The SNCQ mean score for the sample was $50.589( \pm 8.83)$.

3.4. Factors Associated with Clinical Competence. In a bivariate logistic regression analysis, religion, job, social support, university where students belong, year of study, theoretical class attendance, skill lab (demonstration) attendance, ward attendance, and their perception toward the clinical teaching environment were factors associated with clinical competence. However, in multivariate analysis, social support, university where students belong, year of study, theory class attendance, and their perception toward the clinical teaching environment were significantly associated with clinical competence (Table 2).

\section{Discussion}

The present study revealed that overall $48.7 \%$ of the study participants perceived themselves as competent. The SNCQ mean score for the sample was $50.59 \pm 8.83$ (mean \pm SD). This result $(48.7 \%)$ is similar with the study reported from another study as $47.8 \%$ of student nurses evaluated themselves
TABLE 1: Sociodemographic characteristics of the respondents, at The University of Gondar and Bahir Dar University, Amhara Regional States, Ethiopia, $2015(n=234)$.

\begin{tabular}{|c|c|c|}
\hline Characteristics & Number & Percent \\
\hline \multicolumn{3}{|l|}{ Sex } \\
\hline Male & 176 & 75.2 \\
\hline Female & 58 & 24.8 \\
\hline \multicolumn{3}{|l|}{ Age } \\
\hline $18-24$ & 212 & 90.6 \\
\hline $25-34$ & 22 & 9.4 \\
\hline \multicolumn{3}{|l|}{ Marital status } \\
\hline Single & 224 & 95.7 \\
\hline Married & 10 & 4.3 \\
\hline \multicolumn{3}{|l|}{ Religion } \\
\hline Orthodox & 168 & 71.8 \\
\hline Muslim & 44 & 18.8 \\
\hline Protestant & 22 & 9.4 \\
\hline \multicolumn{3}{|l|}{ Employment } \\
\hline Yes & 18 & 7.7 \\
\hline No & 216 & 92.3 \\
\hline \multicolumn{3}{|l|}{ Social support } \\
\hline Low social support & 30 & 12.8 \\
\hline Moderate social support & 76 & 32.5 \\
\hline High social support & 128 & 54.7 \\
\hline \multicolumn{3}{|l|}{ University you belong to } \\
\hline University of Gondar & 138 & 59 \\
\hline Bahardar University & 96 & 41 \\
\hline \multicolumn{3}{|l|}{ Year of study } \\
\hline Third & 100 & 42.7 \\
\hline Fourth & 134 & 57.3 \\
\hline \multicolumn{3}{|l|}{$\begin{array}{l}\text { Attended all theory (lecture) } \\
\text { classes }\end{array}$} \\
\hline Yes & 218 & 93.2 \\
\hline No & 16 & 6.8 \\
\hline \multicolumn{3}{|c|}{ Attended all demonstrations } \\
\hline Yes & 188 & 80.3 \\
\hline No & 46 & 19.7 \\
\hline \multicolumn{3}{|c|}{ Attended all clinical practice } \\
\hline Yes & 216 & 92.3 \\
\hline No & 18 & 7.7 \\
\hline
\end{tabular}

as having high or very high clinical competence [21] and 53\% of student nurses prepared themselves for different domains of nursing role [22]. The mean score of this finding is lower than the cohort study using the same tool that revealed SNCQ mean score of $60.16 \pm 6.52$ (mean \pm SD) and $59.50 \pm$ 7.25 (mean $\pm \mathrm{SD}$ ), respectively, and the overall self-reported competency mean scores were $59.81 \pm 6.88$ (mean \pm SD) [23] . Another prospective study indicated that the mean score of SNCQ for the sample was $57 \pm 7.9$ (mean \pm SD) [24]. A recently published study also revealed that the overall mean 
TABLE 2: Bivariate and multivariate logistic regressions analysis of factors associated with clinical competence, at The University of Gondar and Bahir Dar University, Amhara regional states, Ethiopia, $2015(n=234)$.

\begin{tabular}{|c|c|c|c|c|c|}
\hline \multirow{2}{*}{ Variables } & \multicolumn{2}{|c|}{ Clinical competence } & \multicolumn{2}{|c|}{ OR with $95 \% \mathrm{CI}$} & \multirow{2}{*}{$p$ value } \\
\hline & High & Low & Crude & Adjusted & \\
\hline Religion & & & & & $<0.001$ \\
\hline Orthodox & $86(51.2)$ & $82(48.8)$ & 1 & 1 & \\
\hline Muslim & $24(54.5)$ & $20(45.5)$ & $1.14(0.588,2.227)$ & - & \\
\hline Protestant & $4(18.2)$ & $18(81.8)$ & $0.21(0.069,0.653)$ & - & \\
\hline \multicolumn{6}{|l|}{ Do you have a job other than learning? } \\
\hline Yes & $12(66.7)$ & $6(33.3)$ & 1 & 1 & \\
\hline No & $102(47.2)$ & $114(52.8)$ & $0.45(0.809,6.173)$ & - & \\
\hline Social support & & & & & 0.039 \\
\hline Low social support & $10(33.3)$ & $20(66.7)$ & 1 & 1 & \\
\hline Moderate social support & $36(47.4)$ & $40(52.6)$ & $1.8(1.264,6.682)$ & $5.87(1.346,9.586)^{*}$ & \\
\hline High social support & $68(53.1)$ & $60(46.9)$ & $2.27(1.714,4.118)$ & $6.27(1.741,7.608)^{*}$ & \\
\hline University & & & & & 0.009 \\
\hline University of Gondar & $56(40.6)$ & $82(59.4)$ & 1 & 1 & \\
\hline Bahardar University & $58(60.4)$ & $38(39.6)$ & $2.23(0.263,0.761)$ & $3.20(1.331,7.694)^{*}$ & \\
\hline Year of study & & & & & $<0.001$ \\
\hline Third year & $28(28)$ & $72(72)$ & 1 & 1 & \\
\hline Fourth year & $86(64.2)$ & $48(35.8)$ & $4.61(2.628,8.077)$ & $1.89(4.760,18.510)^{*}$ & \\
\hline Attended all theoretical classes & & & & & 0.002 \\
\hline Yes & $110(50.5)$ & $108(49.5)$ & 1 & 1 & \\
\hline No & $4(25)$ & $12(75)$ & $0.33(0.102,1.046)$ & $0.83(0.017,0.412)^{*}$ & \\
\hline \multicolumn{6}{|c|}{ Attended all the skill lab (demonstration) class } \\
\hline Yes & $86(45.7)$ & $102(54.3)$ & 1 & 1 & \\
\hline No & $28(60.9)$ & $18(39.1)$ & $1.84(0.281,1.047)$ & - & \\
\hline Attended all clinical (ward) practice & & & & & 0.002 \\
\hline Yes & $104(48.1)$ & $112(51.9)$ & 1 & 1 & \\
\hline No & $10(55.6)$ & $8(44.4)$ & $1.35(0.282,1.954)$ & - & \\
\hline Perceived clinical environment & & & & & 0.037 \\
\hline Not recommend & $2(9.1)$ & $20(90.9)$ & 1 & 1 & \\
\hline Poor & $38(39.6)$ & $58(60.4)$ & $6.55(1.447,19.658)$ & $5.65(1.837,13.453)^{*}$ & \\
\hline Fair & $32(55.2)$ & $26(44.8)$ & $12.31(2.631,24.578)$ & $7.31(2.790,15.356)^{*}$ & \\
\hline Good & $42(72.4)$ & $16(27.6)$ & $26.25(4.497,23.350)$ & $9.31(3.260,19.967)^{*}$ & \\
\hline
\end{tabular}

${ }^{*}$ Statistically significant at $p<0.05$.

was $66.7 \pm 15.7$ (mean \pm SD). About $63 \%$ of the participants reported their nurse competence as good and $25.8 \%$ as very good [25].

A cross-sectional study conducted among new graduated nurses using the Nurse Competence Scale tool revealed that overall $83 \%$ of the newly graduated nurses reported their competence as good and $16 \%$ of them reported it as very good [26]. The difference could be attributed to the variations of the socioeconomic status of the country in order to use different teaching aid such as high fidelity simulation, pedagogy, and difference in clinical teaching environment. Studies revealed that those students who learn based on simulation reported themselves as quite prepared for practice than the control group [27]. Competence development is not a linear process. Benner states that nurses are not novices, competent, or experts in all situations; that is, competence is dependent on the actual situation and context [22].
Regarding the associated factors, those students who had moderate social support were more than five times [AOR = 5.87, CI: $1.346,9.586]$ and high social support were more than six times $[\mathrm{AOR}=6.27, \mathrm{CI}: 1.741,7.608]$ more likely to perceive themselves as more competent than those students who had low social support. These results were consistent with the previous study $[28,29]$. This might be due to the fact that lack of social support especially in terms of the economy may hinder the student from getting different teaching material such as handout and transportation cost to reach different clinical teaching area. Moreover, lack of support affects individual self-learning motivation.

Those students who participated from Bahir Dar University were more than three times $[\mathrm{AOR}=3.20, \mathrm{CI}: 1.331$, 7.694] more likely to perceive themselves as more competent than those students who participated from The University of Gondar. This might be due to the number of students 
attending in one class (e.g., if we take the number of students from fourth year, 41, compared to 81 from Gondar University). This is due to the fact that as the number of students in a class is small, they may get more chance for active participation in different procedure and get more supportive feedback that help them to feel confident. This explanation is also supported by another study that revealed those mentors who followed few nursing students were happier to supervise their students and during evaluation also their students have higher nursing competencies [30]. Another explanation may be also that those students who participated from the Bahir Dar University overestimated their competence compared to those students who participated from The University of Gondar.

Fourth-year nursing students were around two times $[\mathrm{AOR}=1.89(4.760,18.510)]$ more likely competent compared to third-year nursing students. This finding is consistent with another study [31]. This may be due to the fact that the longer duration of the study time gives them more chance to clarify and redemonstrate the different procedure that may contribute to their confidence. This explanation is supported by another study [32].

Those students who attended all the theoretical classes were about eighty-three percent $[\mathrm{AOR}=0.83(0.017,0.412)]$ more likely to perceive themselves as competent compared to those who did not attend all the theoretical classes. This finding is supported by other studies $[16,17]$. This may be due to the fact that those students who attended the theoretical classes easily understand and implement their theoretical knowledge in the real clinical environment compared to those who missed the theoretical class.

Those students who perceived their clinical environment as poor were more than five times $[\mathrm{AOR}=5.65, \mathrm{CI}$ : 1.837, 13.453], as fair were more than seven times $[\mathrm{AOR}=7.31$, CI: $2.790,15.356]$, and as good were more than nine times [AOR =9.31, CI: 3.260, 19.967] more likely competent than those students who did not recommend their clinical environment for others. These results were consistent with the previous studies that showed that learning environments that welcome and actively encourage students' participation in patient care have been identified by undergraduate students as important contributors to transform theory into practice $[15,33]$. This result showed that the importance of using the available resource and searching for other opportunities is better than simply missing the minimum or list available resource.

Although the current study did not reveal any significant association between attending clinical practice and skill laboratory (demonstration), a number of studies indicated the importance of attending clinical practice and skill laboratory if both areas are utilized properly by the concerned bodies (student, instructors, preceptors, and staff nurses). In this study, the inconsistence of the result with other findings may be due to the poor relationship between student nurses and their clinical instructors, preceptors, and staff nurses. Studies revealed that students assigned in the clinical area without an effective mentor did not have the opportunities to practice in more complex tasks; instead, they found themselves repeating routine tasks in which they are already proficient [7]. The other possible explanation may be that the students themselves may not be motivated to participate in self-directed learning. From this, it is possible to conclude that the effect of shared responsibilities of all stakeholders (i.e. instructors, preceptors, staff nurse, the students and higher officials) is to prepare competent newly graduated generation. Further research is required to see the integration of attending clinical and skill lab on perceived clinical competence in the study area.

Limitations of the Study. This study has some important limitations that should be kept in mind when interpreting the results. First, the cross-sectional nature of the study design does not confirm definitive cause and effect relationship. Second, the study was based on self-reported information provided by students which may potentially lead to bias that may have occurred because of the respondents' interpretation of the questions or desire to report their feeling that may increase the prevalence of the problem. Third, clinical environment is measured with one item that may not address the different dimensions of clinical environments that may lead to lack of important variable for the competence of student.

\section{Conclusion}

In this study, more than half of the study participants perceived themselves as incompetent. Social support, the university they belong to, year of study, attending theory classes, and students' perception toward their clinical teaching environment were factors significantly associated with perceived clinical competence. Therefore, authors suggested that nursing students attend their theoretical class and seek and utilize the available resource (such as peer and instructors). They also suggested that nurse educators give special attention to those who need support and missed their theoretical classes. They also suggested that nurse educators reevaluate the clinical teaching environment to attract and motivate students by identifying the demotivating factors. Further researches that include preceptors, staff nurse, and instructors are suggested in order to view the true image of the students' level of competence. The authors suggested that all professional nurses in the field stand and see the teaching and learning process of the nursing school in order to take corrective action. Further researches that include preceptors, staff nurse, and instructors' clinical perception are suggested in order to view the true image of the students' level of competence. Finally, authors recommend other researches with qualitative and quantitative study methods to see the relation between attending clinical environment and demonstration on perceived clinical competence and supporting the quantitative findings.

\section{Disclosure}

Funder had no role in study design, data collection, analysis, and decision to publish. Berhanu Boru Biffu had full access to all the data in the study and had final responsibility for the decision to prepare the paper and submit it for publication. 


\section{Competing Interests}

The authors declared that there are no competing interests.

\section{Authors' Contributions}

Berhanu Boru Bifftu carried out the paper's conception, analysis, and interpretation of data and drafted the paper. Berihun Assefa Dachew participated in data analysis and commented on and drafted the paper. Bewket Tadesse Tiruneh participated in data analysis, interpretation, and review of the paper. Netsanet Habte Bayu participated in data analysis and review of the paper. Mengistu Mekonnen Kelkay participated in data analysis and commented on and drafted the paper. Netsanet Habte Bayu participated in data analysis and commented on and drafted the paper. All authors read and approved the final draft of the paper.

\section{Acknowledgments}

First of all, the authors would like to thank Nursing Education Partner Initiatives (NEPI) for the inspiration, motivation, and financial support to conduct this research. Second, the authors would like to thank the study subjects for their willingness to participate in the study. Last but not least, the authors' heartfelt thanks go to the supervisors and data collectors for their admirable endeavor during the data collection.

\section{References}

[1] N. G. Ahmed, S. M. Adam, and I. I. A. Al-Moniem, "Patient safety: assessing nurses' perception and developing an improvement plan," Life Science Journal, vol. 8, no. 2, pp. 53-64, 2011.

[2] A. H. White, "Clinical decision making among fourth-year nursing students: an interpretive study," Journal of Nursing Education, vol. 42, no. 3, pp. 113-120, 2003.

[3] S. Sportsman, "Competency education and validation in the United States: what should nurses know?" Nursing Forum, vol. 45, no. 3, pp. 140-149, 2010.

[4] C. J. Klein and E. R. Fowles, "An investigation of nursing competence and the competency outcomes performance assessment curricular approach: senior students' self-reported perceptions," Journal of Professional Nursing, vol. 25, no. 2, pp. 109-121, 2009.

[5] I. Cave, "Nurse teachers in higher education-without clinical competence, do they have a future?" Nurse Education Today, vol. 14, no. 5, pp. 394-399, 1994.

[6] R. E. Boyatzis, The Competent Manager: A Model for Effective Performance, John Wiley \& Sons, New York, NY, USA, 1982.

[7] J. Spouse, "Bridging theory and practice in the supervisory relationship: a sociocultural perspective," Journal of Advanced Nursing, vol. 33, no. 4, pp. 512-522, 2001.

[8] D. S. Lane and V. Ross, "Defining competencies and performance indicators for physicians in medical management," American Journal of Preventive Medicine, vol. 14, no. 3, pp. 229236, 1998.

[9] Examiners TBoNEftSoTaTBoVN, "Differentiated entry level competencies of graduates of Texas nursing programs," 2002.
[10] (ICN). ICoN, Continuing Competence as a Professional Responsibility and Public Right, International Council of Nurses, 2006.

[11] K. Roberts, R. Lockhart, and S. Sportsman, "A competency transcript to assess and personalize new graduate competency," Journal of Nursing Administration, vol. 39, no. 1, pp. 19-25, 2009.

[12] S. Berkow, K. Virkstis, J. Stewart, and L. Conway, "Assessing new graduate nurse performance," Journal of Nursing Administration, vol. 38, no. 11, pp. 468-474, 2008.

[13] L. H. Aiken, R. B. Cheung, D. M. Sloane, and J. H. Silber, "Educational levels of hospital nurses and surgical patient mortality," Journal of the American Medical Association, vol. 290, no. 12, pp. 1617-1620, 2003.

[14] R. Watson, L. Calman, I. Norman, S. Redfern, and T. Murrells, "Assessing clinical competence in student nurses," Journal of Clinical Nursing, vol. 11, no. 4, pp. 554-555, 2002.

[15] M. Bergjan and F. Hertel, "Evaluating students' perception of their clinical placements-testing the clinical learning environment and supervision and nurse teacher scale (CLES+T scale) in Germany," Nurse Education Today, vol. 33, no. 11, pp. 13931398, 2013.

[16] E. S. S. Do and Y. Sook, "Factors influencing clinical competence in nursing students," Journal of Korean Academy of Fundamentals of Nursing, vol. 21, no. 3, pp. 283-291, 2014.

[17] D. G. Buhat-Mendoza, J. N. Mendoza, C. T. Tianela, and E. L. Fabella, "Correlation of the academic and clinical performance of Libyan nursing students," Journal of Nursing Education and Practice, vol. 4, no. 11, 2014.

[18] Education EMo, Harmonized Modular Curriculum for Bachelor of Science in Nursing Program, 2013.

[19] H. Bartlett, L. Westcott, P. Hind, and H. Taylor, An Evaluation of Pre-Registration Nursing Education: A Literature Review and Comparative Study of Graduate Outcomes, Oxford Centre for Health Care, Research and Development, Oxford Brookes University, Oxford, UK, 1998.

[20] G. D. Zimet, S. S. Powell, G. K. Farley, S. Werkman, and K. A. Berkoff, "Psychometric characteristics of the multidimensional scale of perceived social support," Journal of Personality Assessment, vol. 55, no. 3-4, pp. 610-617, 1990.

[21] A. Lofmark, B. Smide, and K. Wikblad, "Competence of newlygraduated nurses-a comparison of the perceptions of qualified nurses and students," Journal of Advanced Nursing, vol. 53, no. 6, pp. 721-728, 2006.

[22] B. Benner, From Novice to Expert. Excellence and Power in Clinical Nursing Practice, Prentice-Hall, Upper Saddle River, NJ, USA, 2001.

[23] W. Lauder, R. Watson, K. Topping et al., "An evaluation of fitness for practice curricula: self-efficacy, support and self-reported competence in preregistration student nurses and midwives," Journal of Clinical Nursing, vol. 17, no. 14, pp. 1858-1867, 2008.

[24] J. Por, L. Barriball, J. Fitzpatrick, and J. Roberts, "Emotional intelligence: its relationship to stress, coping, well-being and professional performance in nursing students," Nurse Education Today, vol. 31, no. 8, pp. 855-860, 2011.

[25] S. Kajander-Unkuri, Nurse Competence of Graduating Nursing Students, Department of Nursing Science, Faculty of Medicine, University of Turku, Finland Annales Universitatis Turkuensis, Painosalama Oy, Turku, Finland, 2015.

[26] S. Wangensteen, Newly Graduated Nurses' Perception of Competence, Critical Thinking and Research Utilization, Karlstad University Studies, 2010. 
[27] J. K. Hayden, R. A. Smiley, M. Alexander, S. Kardong-Edgren, and P. R. Jeffries, "The NCSBN national simulation study: a longitudinal, randomized, controlled study replacing clinical hours with simulation in prelicensure nursing education," Journal of Nursing Regulation, vol. 5, no. 2, pp. S3-S40, 2014.

[28] S. Kajander-Unkuri, R. Suhonen, J. Katajisto et al., "Selfassessed level of graduating nursing students' nursing skills," Journal of Nursing Education and Practice, vol. 4, no. 12, pp. 5164, 2014.

[29] B. D. Cejda, C. A. Casparis, J. H. Rhodes, and K. SealNyman, "The role of social capital in the educational decisions of Hispanic students attending Hispanic serving community colleges," Enrollment Management Journal, vol. 2, no. 1, pp. 3259, 2008.

[30] B. J. P. Gonzalez, Predictors of Mexican American nursing student academic success [Ph.D. dissertation], University of WisconsinMilwaukee, Milwaukee, Wis, USA, 2013.

[31] P. Efren, E. L. F. Molina II, and G. Carla, "Vigonte physical assessment self-efficacy of Libyan nursing students," Journal of Research in Nursing and Midwifery, vol. 3, no. 3, pp. 60-65, 2014.

[32] A. Gardner, S. Hase, G. Gardner, S. V. Dunn, and J. Carryer, "From competence to capability: a study of nurse practitioners in clinical practice," Journal of Clinical Nursing, vol. 17, no. 2, pp. 250-258, 2008.

[33] T. Brown, B. Williams, L. McKenna et al., "Practice education learning environments: the mismatch between perceived and preferred expectations of undergraduate health science students," Nurse Education Today, vol. 31, no. 8, pp. e22-e28, 2011. 


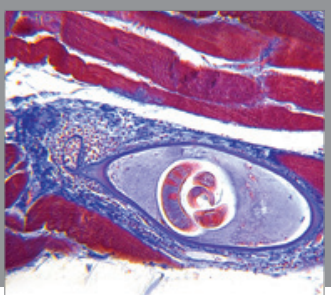

Gastroenterology

Research and Practice
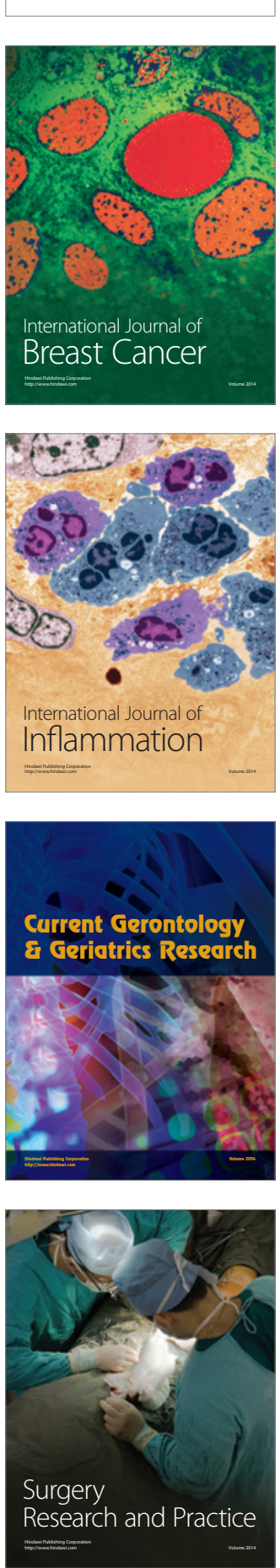

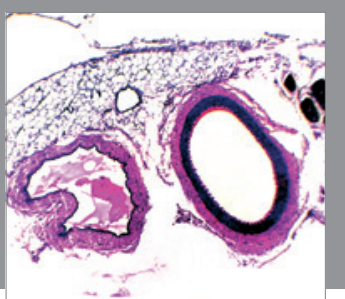

International Journal of Hypertension
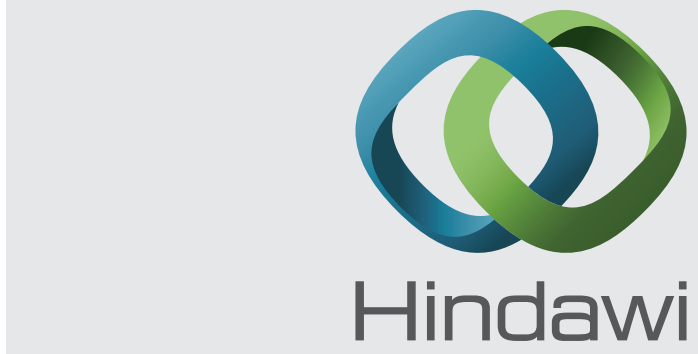

Submit your manuscripts at http://www.hindawi.com
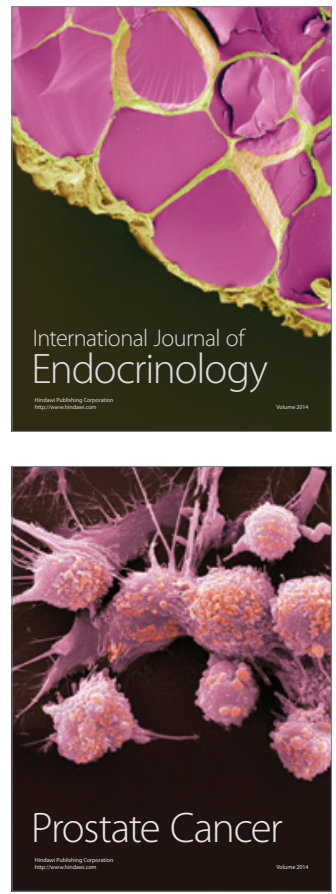

The Scientific World Journal
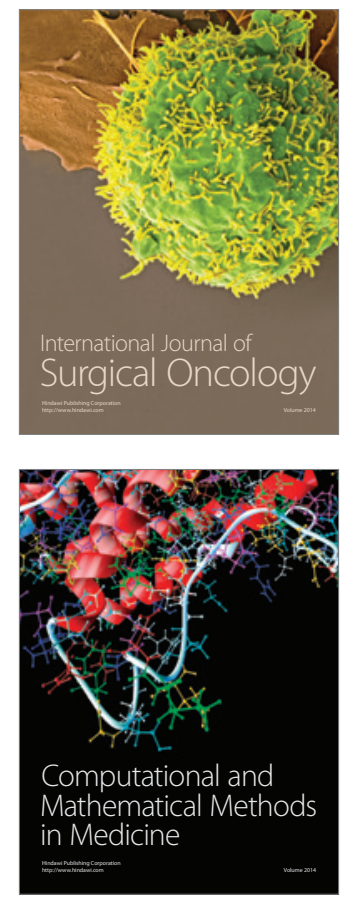
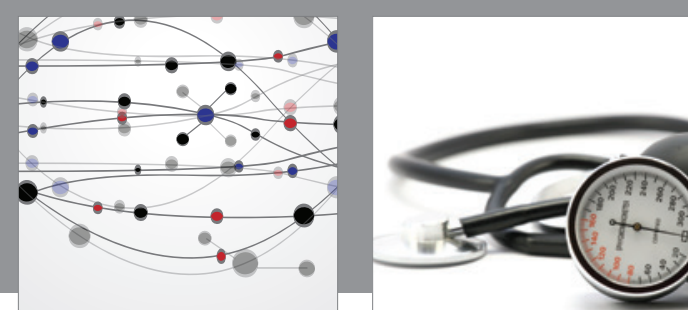

Nursing

Research and Practice

Research and Practice
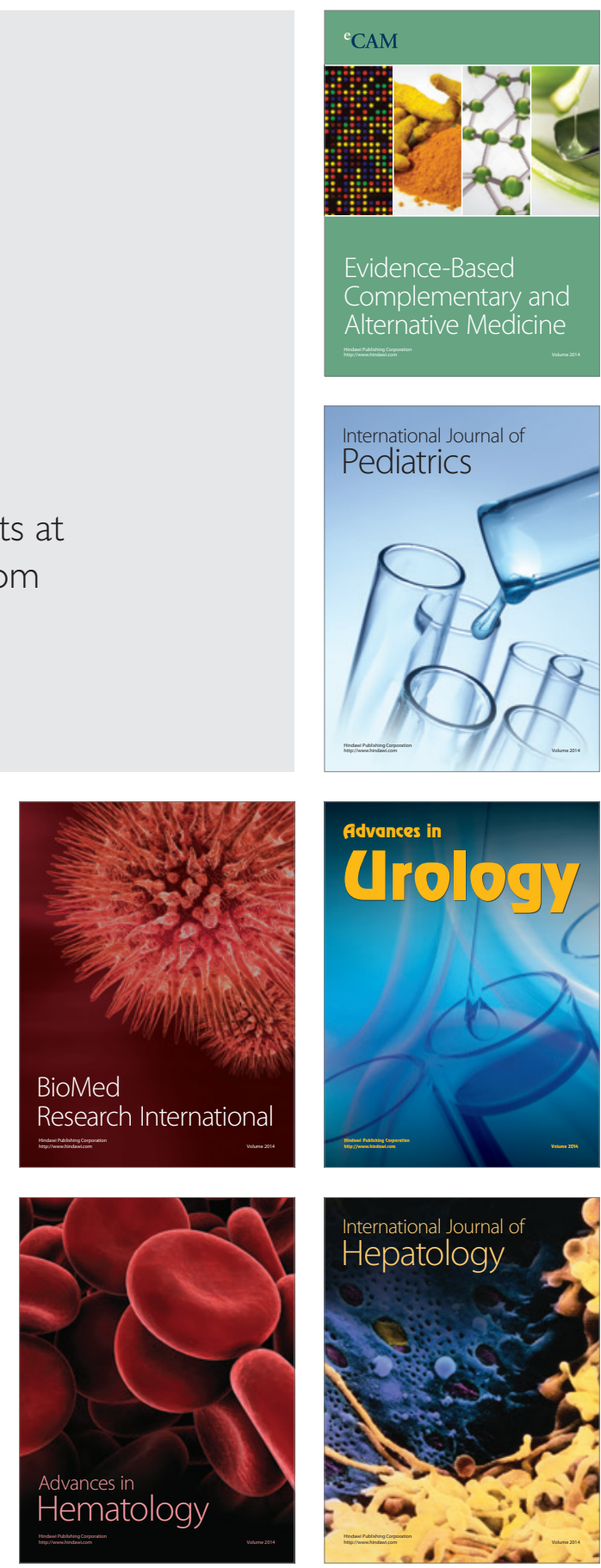
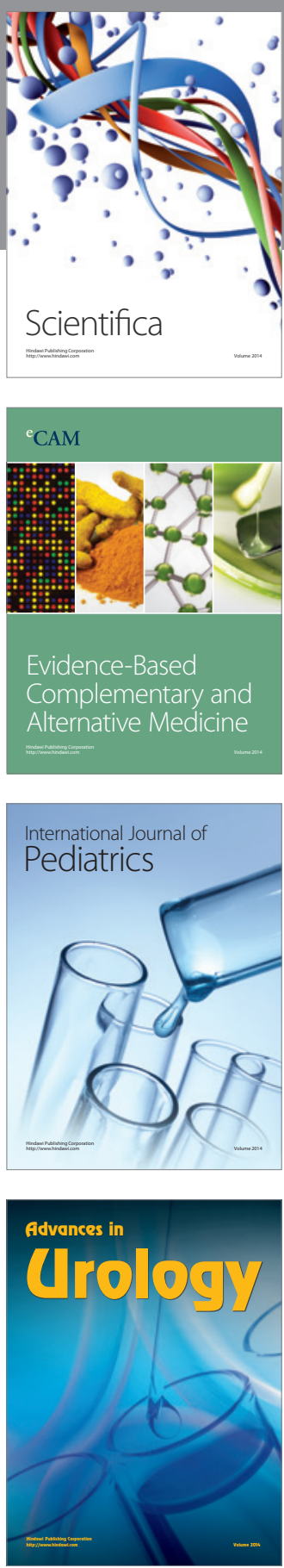

Scientifica

Evidence-Based

Complementary and

Alternative Medicine

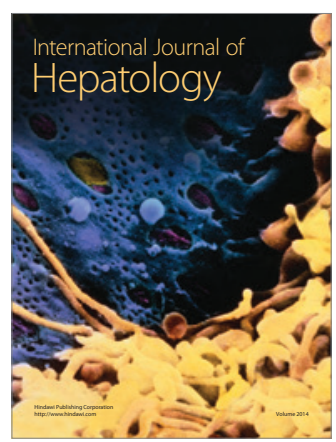

